\title{
Predictors of mortality for hospitalized young adults aged less than 60 years old with severe COVID-19: a retrospective study
}

\author{
Zilong Liu ${ }^{1 \#}$, Jie Liu ${ }^{1 \#}$, Ling Ye ${ }^{1}$, Kaihuan $\mathrm{Yu}^{2}$, Zhe $\mathrm{Luo}^{3}$, Chao Liang ${ }^{4}$, Jiangtian Cao ${ }^{5}, \mathrm{Xu} \mathrm{Wu}^{1}$, \\ Shanqun Li ${ }^{1}$, Lei Zhu', Guiling Xiang ${ }^{1}$ \\ ${ }^{1}$ Department of Pulmonary and Critical Care Medicine, Zhongshan Hospital, Fudan University, Shanghai, China; ${ }^{2}$ Department of Hepatobiliary \\ Surgery, Renmin Hospital, Wuhan University, Wuhan, China; ${ }^{3}$ Department of Critical Care Medicine, Zhongshan Hospital, Fudan University, \\ Shanghai, China; ${ }^{4}$ Department of Anesthesiology, Zhongshan Hospital, Fudan University, Shanghai, China; ${ }^{5}$ Department of Cardiology, Zhongshan \\ Hospital, Fudan University, Shanghai, China \\ Contributions: (I) Conception and design: S Li, L Zhu, G Xiang, Z Liu, J Liu; (II) Administrative support: Z Liu, J Liu; (III) Provision of study \\ materials or patients: Z Liu, J Liu, L Ye, K Yu, Z Luo, C Liang, J Cao, X Wu; (IV) Collection and assembly of data: G Xiang, Z Liu, J Liu; (V) Data \\ analysis and interpretation: Z Liu, J Liu, G Xiang; (VI) Manuscript writing: All authors; (VII) Final approval of manuscript: All authors. \\ \#These authors contributed equally to this work. \\ Correspondence to: Dr. Shanqun Li; Dr. Lei Zhu; Dr. Guiling Xiang. Department of Pulmonary and Critical Care Medicine, Zhongshan Hospital, \\ Fudan University, 180 Fenglin Road, Shanghai 200032, China. Email: li.shanqun@zs-hospital.sh.cn; zhu.lei@zs-hospital.sh.cn; xgl358@126.com.
}

Background: To analyze the clinical characteristics and predictors for mortality of adult younger than 60 years old with severe coronavirus disease 2019 (COVID-19).

Methods: We retrospectively retrieved data for 152 severe inpatients with COVID-19 including 60 young patients in the Eastern Campus of Wuhan University affiliated Renmin Hospital in Wuhan, China, from January 31, 2020 to February 20, 2020. We recorded and analyzed patients' demographic, clinical, laboratory, and chest CT findings, treatment and outcomes data.

Results: Of those 60 severe young patients, 15 (25\%) were died. Male was more predominant in deceased young patients $(12,80 \%)$ than that in recovered young patients $(22,49 \%)$. Hypertension was more common among deceased young patients $(8,53 \%)$ than that in recovered young patients $(7,16 \%)$. Compared with the recovered young patients, more deceased young patients presented with sputum (11, 73\%), dyspnea $(12,80 \%)$ and fatigue $(13,87 \%)$. Only sputum, PSI and neutrophil counts were remained as independent predictors of death in a multivariate logistic regression model. Among ARDS patients, the recovered were administrated with corticosteroid earlier and anticoagulation. The addition of neutrophil counts $>6.3 \times 10^{9} / \mathrm{L}$ to the SMART-COP score resulted in improved area under the curves.

Conclusions: Severe acute respiratory syndrome coronavirus 2 (SARS-Cov-2) infection in young deceased patients appears to cause exuberant inflammatory responses, leading to compromised oxygen exchange, coagulation and multi-organ dysfunction. In addition, young patients with ARDS could benefit from adjuvant early corticosteroid and anticoagulation therapy. The expanded SMART-COP could predict the fatal outcomes with optimal efficiency.

Keywords: Coronavirus disease 2019 (COVID-19); young patients; predictors

Submitted Jan 19, 2021. Accepted for publication Apr 29, 2021.

doi: $10.21037 /$ jtd-21-120

View this article at: http://dx.doi.org/10.21037/jtd-21-120

\section{Introduction}

The novel coronavirus disease 2019 (COVID-19) was firstly identified in December 2019 and was quickly reported worldwide in the following months. The rapid spread of severe acute respiratory syndrome coronavirus 2 (SARS$\mathrm{CoV}-2)$, coupled with a lack of therapeutics, has paralyzed 
the globe. As of January 11, 2021, the World Health Organization had received reports of 89,048,345 laboratoryconfirmed COVID-19 cases and 1,930,265 deaths from 223 countries, territories or areas (1). A cohort study based on early 44,672 cases of China reported that most patients were aged $30-79$ years $(86.6 \%)$, considered mild (80.9\%) and the overall case-fatality rate (CFR) is $2.3 \%$ (2). Despite accurate assessment for CFR is difficult, it could be up to $1 \%$ which is well beyond seasonal influenza at about $0.1 \%(3,4)$. Compared with patients aged over 80 years old $(9.3 \%)$, the estimate of CFR for adults aged under 60 years old is less than $0.2 \%$ (4). Older patients and those with underlying conditions appear to be at the greatest risk for worse outcomes $(5,6)$.

Several severe patients may develop dyspnea and hypoxemia, then exacerbate to life-threatening complications and ultimately, death (5-7). Young COVID-19 patients may also progress into severe illness with poor prognosis, which should be taken seriously. However, little information is available on clinical feature and risk factors for mortality of young patients with severe COVID-19. Furthermore, some studies published to date have been limited by small sample size (8), or lack of adequate information $(9,10)$. To identify risk factors for young patients with severe COVID-19, and determine the optimal case management and prevention strategies, more detailed data are urgently needed.

Herein, we present details of 152 severe inpatients with confirmed COVID-19 in designated hospitals in WuhanRenmin Hospital of Wuhan University between January 31, 2020 and February 20, 2020. The aim was to compare the clinical feature of adult younger than 60 years old with that of patients aged 60 and older. We also attempted to determine predictors for fatal outcomes and therapeutic strategy of young patients with severe COVID-19.

We present the following article in accordance with the STROBE reporting checklist (available at http://dx.doi. org/10.21037/jtd-21-120).

\section{Methods}

\section{Study design and patients}

During the COVID-19 outbreak in December 2019, the Eastern Campus of Wuhan University affiliated Renmin Hospital (Wuhan, China) was one of designated center receiving severe or critically ill referrals from isolation sites, fever clinic of the hospital or other hospitals. We performed an observational cohort study in the Eastern
Campus of Wuhan University affiliated Renmin Hospital. From January 31, 2020 to February 20, 2020, a total of 60 young (defined as younger than 60 years old) severe or critically ill inpatients diagnosed with COVID-19 were enrolled in our study. We also included 92 elderly COVID-19 patients (defined as 60 and older) matched by gender and severity degree of young patients. According to the Guidelines for COVID-19 issued by the National Health Commission of China (7th edition) (11), all included patients were confirmed with COVID-19 and classified as severe or critical (severe mentioned below including severe and critical ill) (Figure S1). The final date of follow-up was March 18, 2020. The study was conducted in accordance with the Declaration of Helsinki (as revised in 2013). This study was approved by the ethics committee of Renmin Hospital, Wuhan University, China (WDRY2020-K048). Individual patient informed consent was waived due to given the non-interventional nature of the study. The identification of patients was anonymized.

\section{Data collection}

Demographic, clinical, laboratory, and chest CT characteristics, treatment and outcomes data were collected retrospectively with information collection forms from electronic medical records. A trained research team from Zhongshan Hospital collected and reviewed the data. Information retrieved included demographic data, comorbidities, symptoms, vital signs at admission, initial laboratory values, chest CT scans, treatment, complication, and outcomes (recovery, death). The clinical type (Table S1) and scores (PSI, CURB65, SMARTCOP, SOFA and APACHE score) were determined within 24 hours at admission (11). Guiling Xiang and Zilong Liu crosschecked the data.

\section{Treatment and outcome}

The therapeutic principles included supportive therapy, antiviral treatment, empirical antimicrobial treatment, oxygen therapy, blood purification if necessary. We should monitor vital signs, oxygen saturation, blood routine, inflammatory marks, lung, liver, kidney, cardiac and blood clotting functions. The complications included acute respiratory distress syndrome (ARDS), acute kidney injury, acute liver injury, acute cardiac injury, and so on (Table S2) (12-15). The outcomes were recovery and death. The criteria for recovery referred to improved respiratory 
symptoms, normal body temperature for at least 3 days, nonprogression in chest CT and two negative results on RTPCR for SARS-CoV-2 for more than 24 hours apart. We compared the clinical characteristics and laboratory findings of the severe young patients with previously reported data for 38 young patients with COVID-19 in Hainan (8), 52 young patients with SARS in Hong Kong (16), and 150 American young patients with H1N1 influenza (17).

\section{Statistical analysis}

We presented continuous variables, categorical variables as median (IQR) and number (\%). The Mann-Whitney U test, chi-square test and Fisher's exact tests were used to compare continuous variables and categorical variables. We used univariate and multivariate logistic regression model to determine the predictors of death and to estimate odds ratios and $95 \%$ confidence intervals. Hosmer-Lemeshow statistic was selected to determine goodness of fit. The cumulative mortality rates were described using KaplanMeier method. Time to events (death) were defined as the duration from hospital admission to death. A two-sided $\mathrm{P}$ value less than 0.05 was considered significant for all tests. All statistical analysis was performed using SPSS, version 21.0 (IBM SPSS).

\section{Results}

\section{Demographics and clinical characteristics}

A total of 152 hospitalized severe cases with confirmed COVID-19 were enrolled, with 60 patients categorized into young-aged patients and 92 patients categorized into oldaged patients; $28(18 \%)$ of the patients were critically ill at admission. As shown in Table 1, 34 (57\%) young patients and $56(61 \%)$ who were elderly were male. Overall, 26 (43\%) young patients and 67 (73\%) elderly patients had coexisting illness. Hypertension, diabetes and cardio-cerebrovascular disease were predominant comorbidity in severe patients.

From illness onset, common symptoms were fever, dry cough and fatigue in both young patients and elderly patients (Table 1). Dyspnea was less common in young patients $(20,33 \%)$ than in elderly patients $(54,59 \%)$. Fever was initial symptom of 12 deceased young patients.

Masculinity was more primary in deceased young patients $(12,80 \%)$ than in recovered young patients $(22$, $49 \%)$. Compared with recovered young patients $(16,36 \%)$, deceased young patients were more likely to have coexisting illness (10, 67\%). The deceased young patients were much more likely to report sputum, dyspnea and fatigue than recovered young patients.

As show in Table 2, all deceased young patients and only 11 (24\%) recovered young patients had high PSI score $(\geq 90)$. The deceased young patients had higher CURB-65 scores than recovered young patients. Higher SMART-COP score were found in deceased young patients $\{6,[5-6]\} ; 14$ (93\%) deceased young patients and only $5(11 \%)$ recovered young patients had high SMART-COP score $(\geq 5)$.

As shown in Table 3, fourteen (93\%) deceased young patients and $8(18 \%)$ recovered young patients had abnormal oxygenation index (oxygenation index $<240 \mathrm{mmHg}$ ). The duration from symptom onset to hospital admission of recovered young patients and deceased young patients were 11 days ( $8-15$ days) and 10 days ( $7-13$ days).

\section{Laboratory parameters and chest $C T$}

There were substantial differences in laboratory values between young and elderly severe patients (Table 2), including blood routine, inflammatory index, coagulation function, liver function, kidney function, cardiac function. The elderly patients had lower lymphocytes and CD8+ T cell counts as well as lower levels of albumin; 145 of the 152 included patients had bilateral involvement of CT scan (Figure 1). On admission, the SOFA and APACHE II in young patients were lower than in elderly patients.

As shown in Table 2, only 2 (4\%) young patients who recovered and 7 (47\%) who died had leukocytosis (WBC count $\left.\geq 9.5 \times 10^{9} / \mathrm{L}\right)$. Deceased young patients had more severe lymphopenia than recovered young patients; 14 (93.33\%) deceased young patients and $6(13 \%)$ recovered young patients had neutrophils above $6.3 \times 10^{9} / \mathrm{L}$. Median lymphocytes were significantly lower in deceased young patients (0.6, 0.5-0.9). Concentrations of CRP and PCT were significantly higher in deceased young patients than in recovered young patients; $38(84 \%)$ recovered young patients and $15(100 \%)$ deceased young patients developed bilateral involvement on chest CT scan.

\section{Treatments and outcome}

Of the 60 young patients, 57 (95\%) received antiviral therapy received empirical antibiotic treatment (Table 3); 15 (20\%) young patients received high-flow oxygen therapy and $9(15 \%)$ received noninvasive ventilation; 22 (49\%) recovered young patients and $11(73 \%)$ deceased young 
Table 1 Demographic and clinical presentation in patients with COVID-19 in matched case-control study

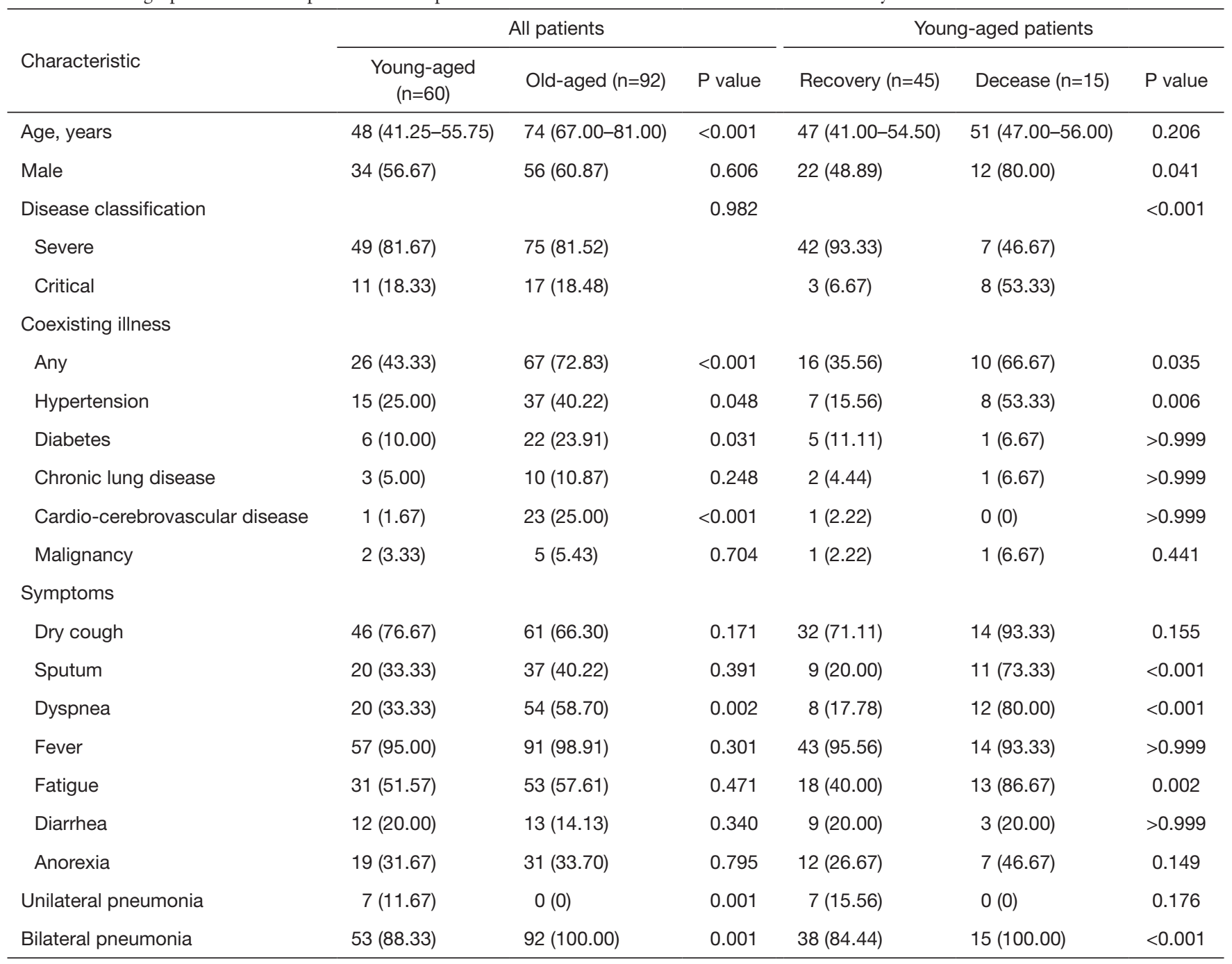

Data are median (IQR), n (\%). P values were calculated by Mann-Whitney U test, $\chi^{2}$ test, or Fisher's exact test, as appropriate. COVID-19, coronavirus disease 2019.

patients received corticosteroids (Table 3).

Among the deceased young patients, ARDS (15, 100\%), acute cardiac injury $(3,20 \%)$ and acute liver injury $(4,27 \%)$ were numerous which associated with the clinical outcome potentially (Table 2$)$. The severe elderly patients $(50,54 \%)$ had cumulative mortality than the severe young patients $(15,25 \%$; Figure $2 A)$. Among the 15 severe young patients who died, five were younger than 50 years old, three received mechanical ventilation, one received continuous renal replacement therapy and one had pneumothorax and pneumomediastinum (Table S3).

The comparison of severe young COVID-19 patients with non-severe young patients in China showed that severe young patients had higher incidence of abnormal values of certain variables indicating negative association with the clinical outcome, such as fever (95\% vs. $79 \%)$, cough (77\% vs. 39\%), dyspnea (33\% vs. 18.33\%), hypertension ( $25 \%$ vs. $13 \%)$, diabetes ( $10 \%$ vs. $3 \%)$, leukocytosis $(15 \%$ vs. $5 \%)$ and ARDS (43.33\% vs. $5 \%$ ) (Table S4). The mortality in severe young patients $(15,25 \%)$ was much higher than non-severe young patients $(2,5 \%)$. When compared with young patients with SARS, young patients with COVID-19 had much low incidence of cough, high prevalence of dyspnea and usage rate of corticosteroids. The mortality in two groups were similar ( $5 \%$ vs. $4 \%$ ). Compared with the young with H1N1 influenza, young 
Table 2 Initial laboratory indices and complications in patients with COVID-19 in matched case-control study

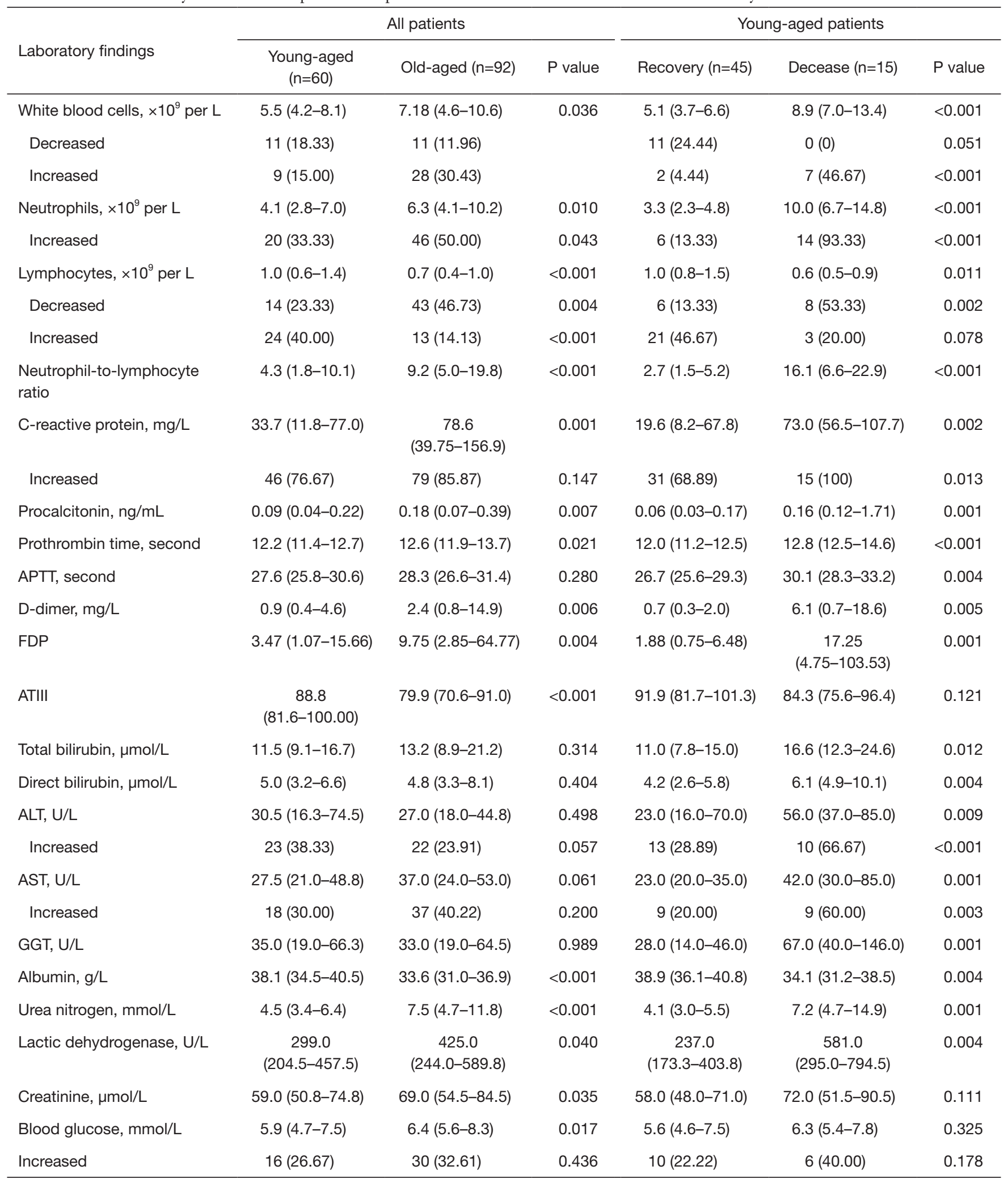

Table 2 (continued) 
Table 2 (continued)

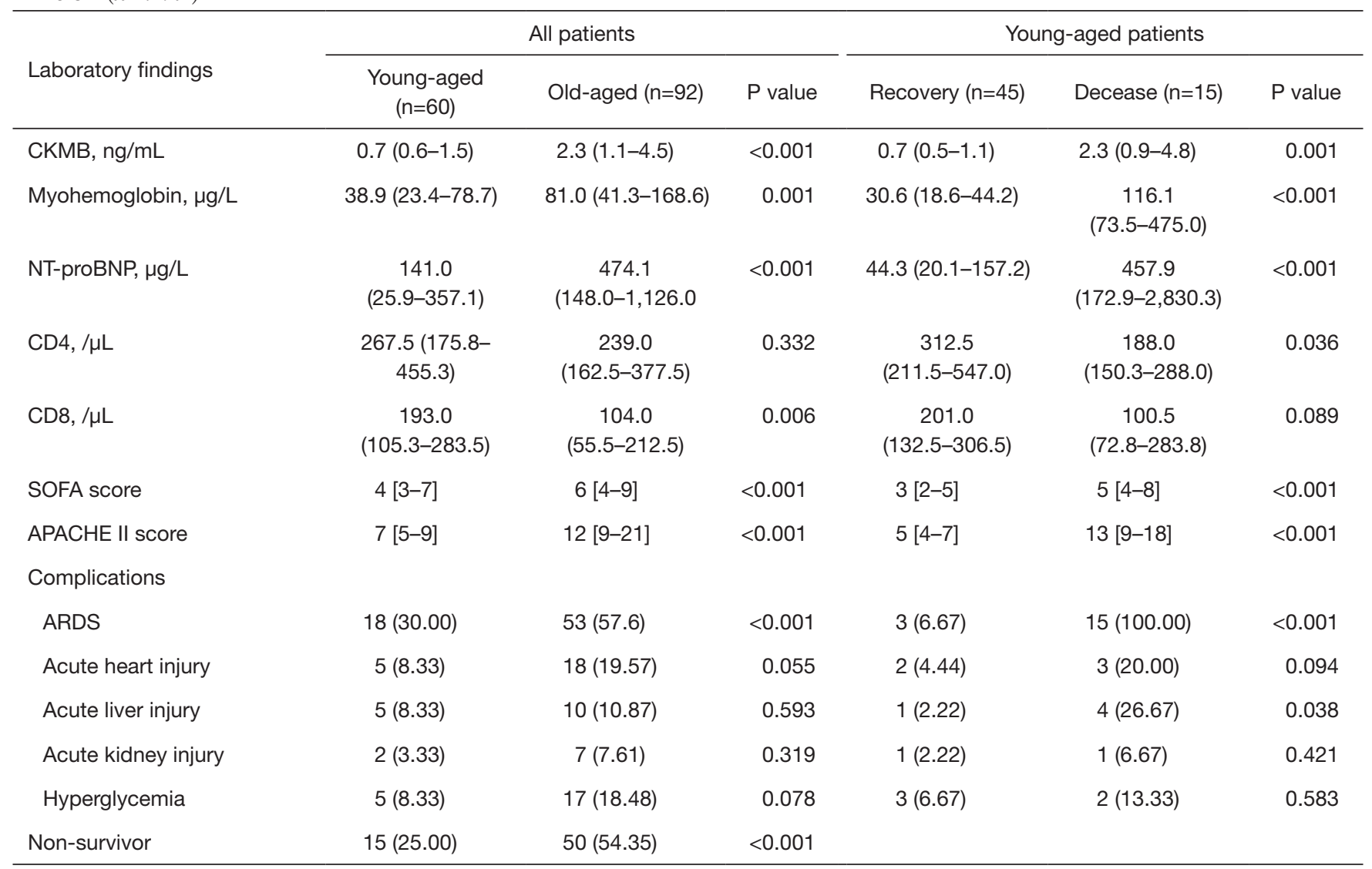

Data are median (IQR), n (\%). P values were calculated by Mann-Whitney $U$ test, $\chi^{2}$ test, or Fisher's exact test, as appropriate. COVID-19, coronavirus disease 2019; SOFA, sequential organ failure assessment; ALT, alanine aminotransferase; AST, aspartate amino transferase; GGT, gamma-glutamyl transpeptidase; APTT, activated partial thromboplastin time; FDP, fibrinogen degradation product; CKMB, creatine kinase isoenzymes; ARDS, acute respiratory distress syndrome.

patients with COVID-19 had fewer respiratory symptoms (e.g., rhinorrhea, cough and dyspnea) and lower prevalence of abnormal liver function and ARDS. Patients who were administrated with corticosteroids were divided into three groups including corticosteroids apply before ARDS was diagnosed $(n=7)$, corticosteroids apply within $48 \mathrm{~h}$ when ARDS was diagnosed $(n=10)$, corticosteroids apply later than $48 \mathrm{~h}$ when ARDS was diagnosed $(\mathrm{n}=5)$. Compared with corticosteroids apply later than $48 \mathrm{~h}$ when ARDS was diagnosed, corticosteroids apply within $48 \mathrm{~h}$ when ARDS was diagnosed had lower mortality $(\mathrm{P}=0.001)$ and fewer hospital stays $(\mathrm{P}<0.001)$ (Table 4$)$.

\section{Clinical characteristics, treatments of young COVID-19 patients with ARDS}

Among young COVID-19 patients with ARDS, the recovered had larger maximum dose of corticosteroids, time interval of corticosteroids apply after ARDS were shorter than the deceased (Table 5). Compared with the deceased, the SOFA, APACHE II score and oxygenation index when corticosteroids apply were better in the recovered which indicated early administration of corticosteroids might improve prognosis for ARDS.

\section{Risk analysis and prediction of death in severe young patients}

Only sputum, PSI and neutrophil counts remained as independent predictors of death in a multivariate logistic regression model (Table 6). The data were well fitted by Hosmer-Lemeshow test $(\mathrm{P}=0.448)$. As shown in Figure 3, increasing severity of COVID-19 according to PSI, CURB65 and SMART-COP were associated with gradual increase 
Table 3 Clinical characteristics, treatments of young patients with severe COVID-19

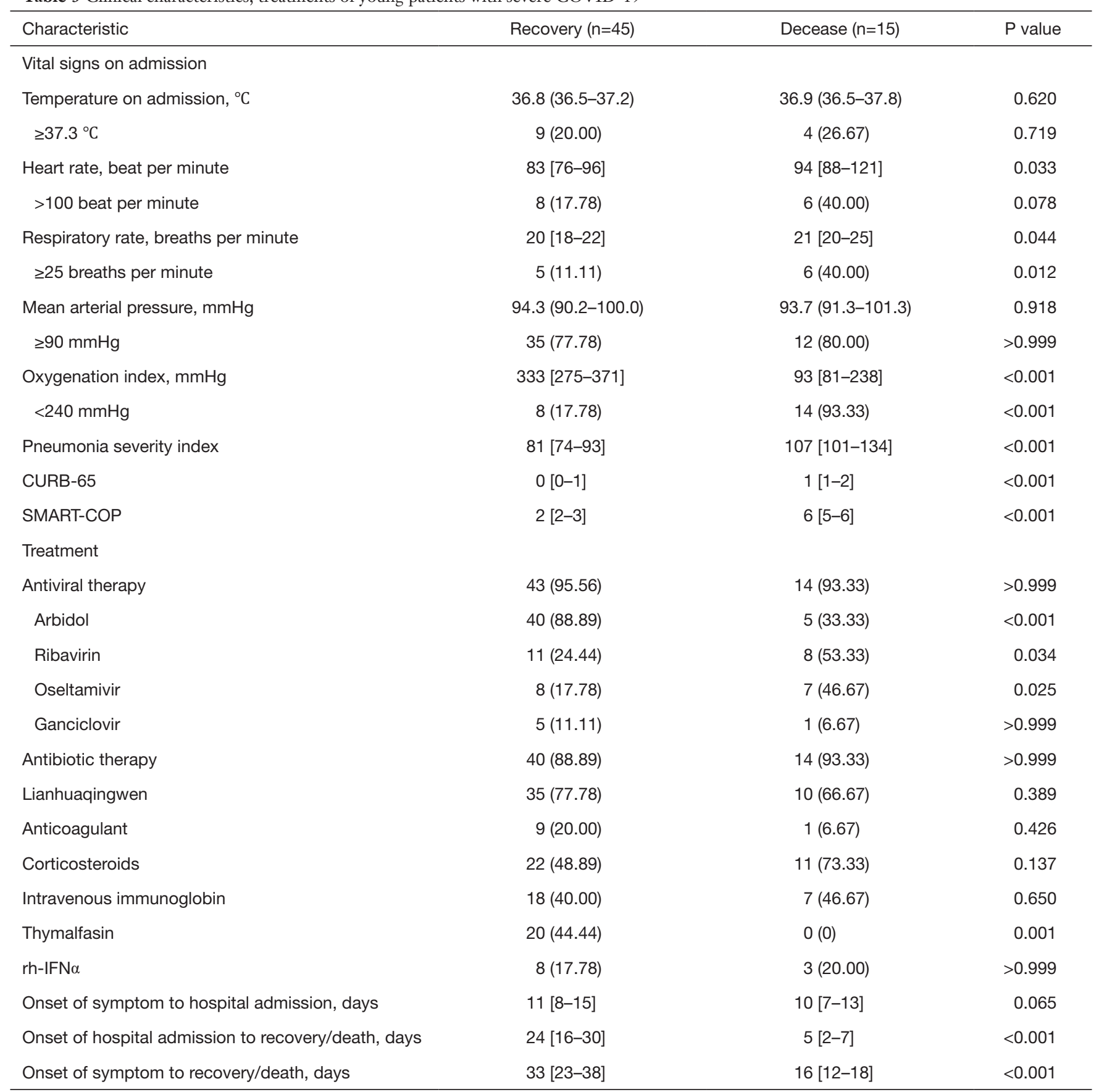

Data are median (IQR), n (\%). P values were calculated by Mann-Whitney U test, $\chi^{2}$ test, or Fisher's exact test, as appropriate. COVID-19, coronavirus disease 2019.

of neutrophil counts, respectively.

Figure 4 demonstrate the ROC curves and cut-off values using the PSI, CURB-65, SMART-COP and neutrophil counts for death in severe young patients. If we added neutrophil counts $>6.3 \times 10^{9} / \mathrm{L}$ as an additional criterion to the SMART-COP score (SMART-COP-N score), the AUCs were improved compared to the SMART-COP score alone. A cut-off value of SMART-COP-N $\geq 6$ combined the best sensitivity and specificity for death $(93.3 \%, 91.1 \%)$ which were verified by Kaplan-Meier analysis (Figure 2B). 

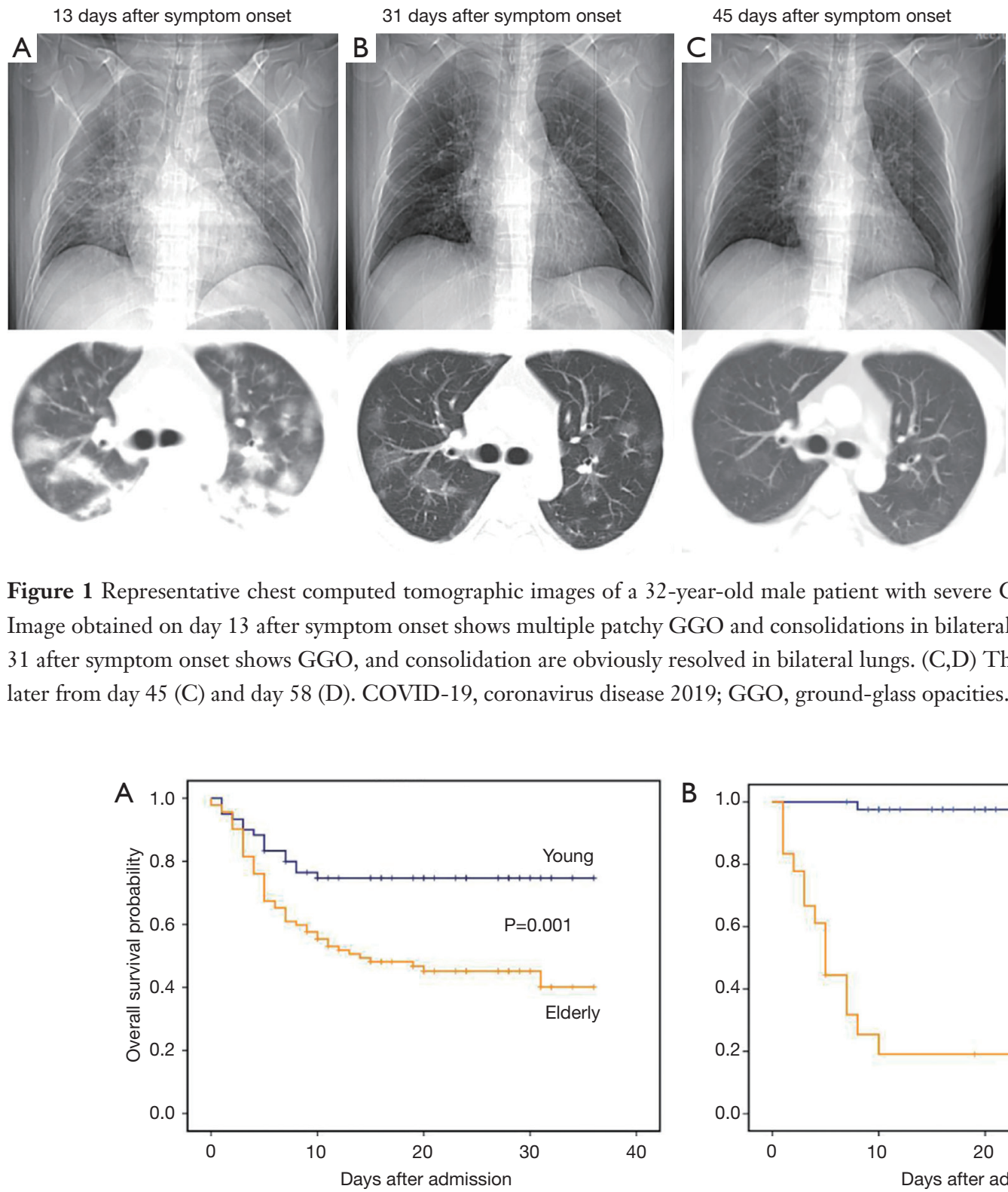

58 days after symptom onset

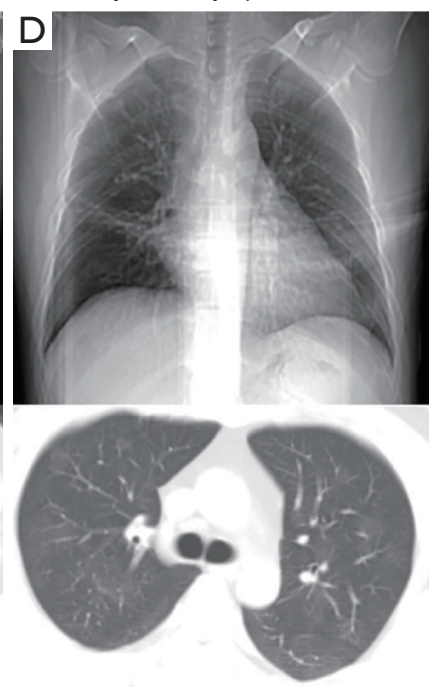

Figure 2 Kaplan-Meier analysis for prediction of hospital mortality. (A) Survival curve in severe patients who were young and elderly; (B) survival curve in severe young patients according to SMART-COP-N. SMART-COP-N, SMART-COP score including neutrophil counts $>6.3 \times 10^{9} / \mathrm{L}$.

\section{Discussion}

As COVID-19 pandemic 'accelerating', the world witness record rise in death toll. Adult under 60 years old were deemed as low risk for poor prognosis, however, a few of them still progressed to severe or critically ill, and even die (10). Hence, it is urgent to see into the clinical features and identify the risk factors related to fatal outcome in young

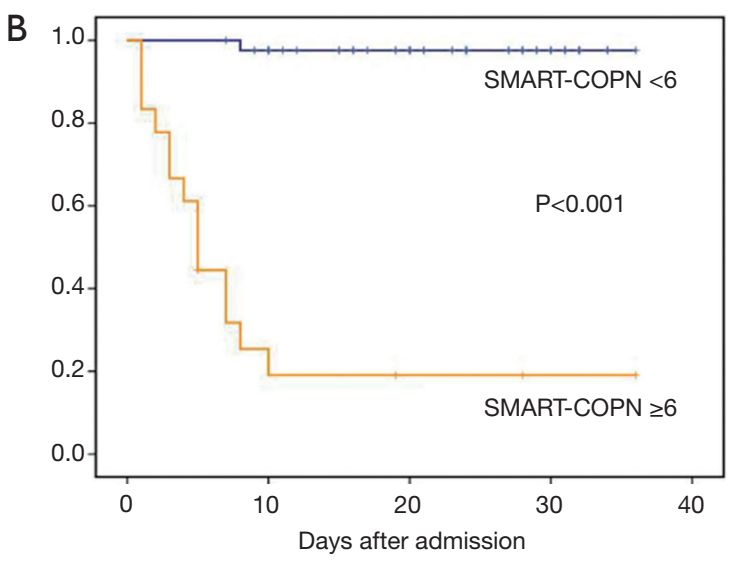

patients with COVID-19. We reported that masculinity was more predominant in deceased young patients compared with those who recovered. Underlying disease (particularly hypertension), hypoxia-related symptoms, like sputum, dyspnea or fatigue, were related to the high mortality. The young patients who died were more susceptible to activate exuberant inflammatory responses and developed 
Table 4 Clinical characteristics, treatments of young COVID-19 patients who were administrated with corticosteroids

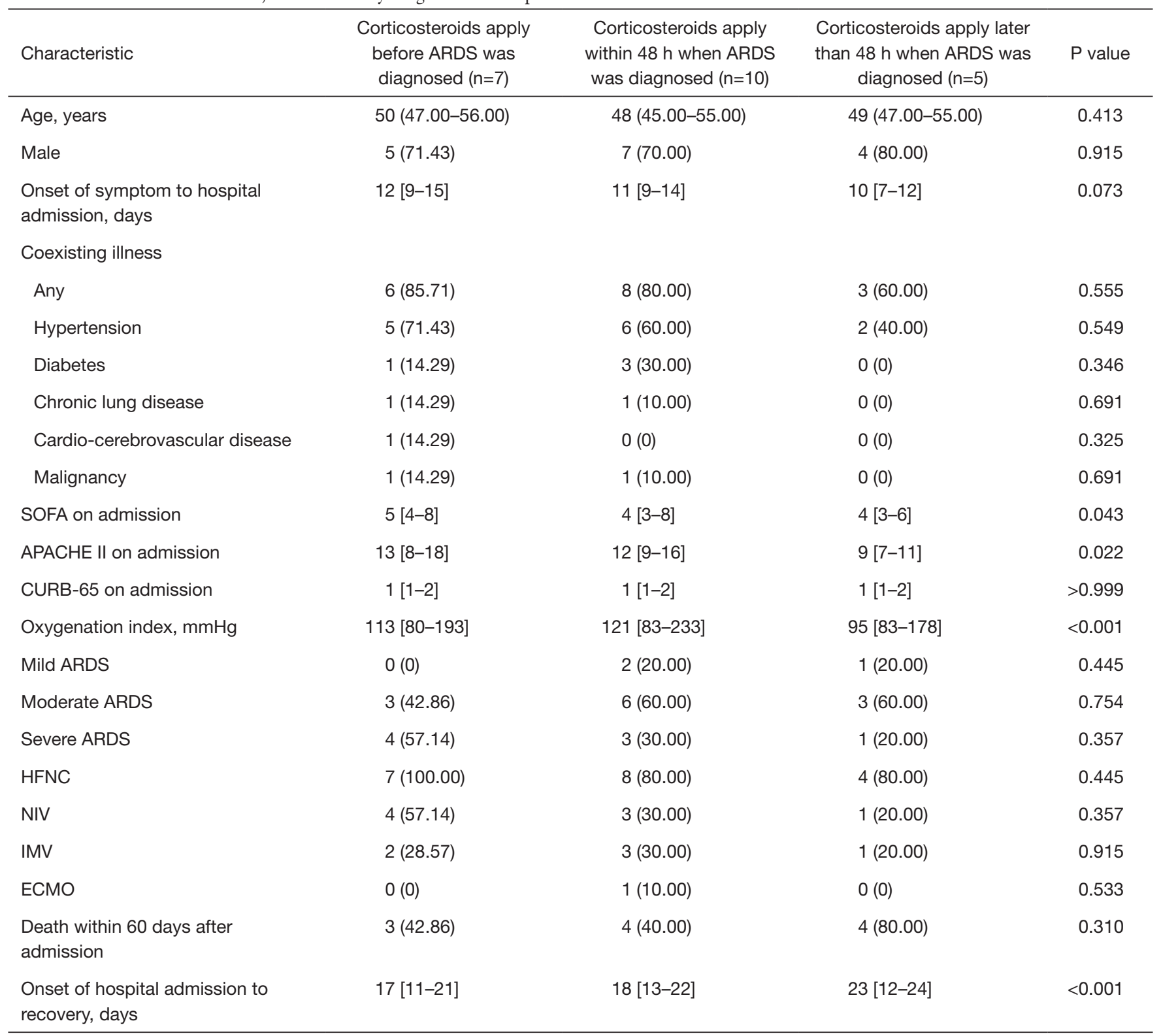

Data are median (IQR), n (\%). COVID-19, coronavirus disease 2019; SOFA, sequential organ failure assessment; ARDS, acute respiratory distress syndrome; HFNC, high-flow nasal cannula oxygen therapy, NIV, non-invasive ventilation, IMV, invasive mechanical ventilation; ECMO, extracorporeal membrane oxygenation.

coagulation and multi organ dysfunction, especially ARDS, acute cardiac injury and acute liver injury. Early administration of corticosteroids might improve prognosis for ARDS. Age is considered as an important risk factor in COVID-19 (8). Compared to young patients, more elderly patients had coexisting illness. Dyspnea was less common in young patients than in elderly patients. There were substantial differences in laboratory values between young and elderly severe patients, including blood routine, inflammatory index, coagulation function, liver function, kidney function, cardiac function. Thus, the old people are the high-risk population during the $2019-\mathrm{nCoV}$ infection.

In the terminal stage of SARS-CoV-2 infection, dysregulated of immune response result in strong host inflammation and fatal disease, which is similar to SARS$\mathrm{CoV}$ and MERS-CoV infection (18-20). Exaggerated 
Table 5 Clinical characteristics, treatments of young COVID-19 patients with ARDS

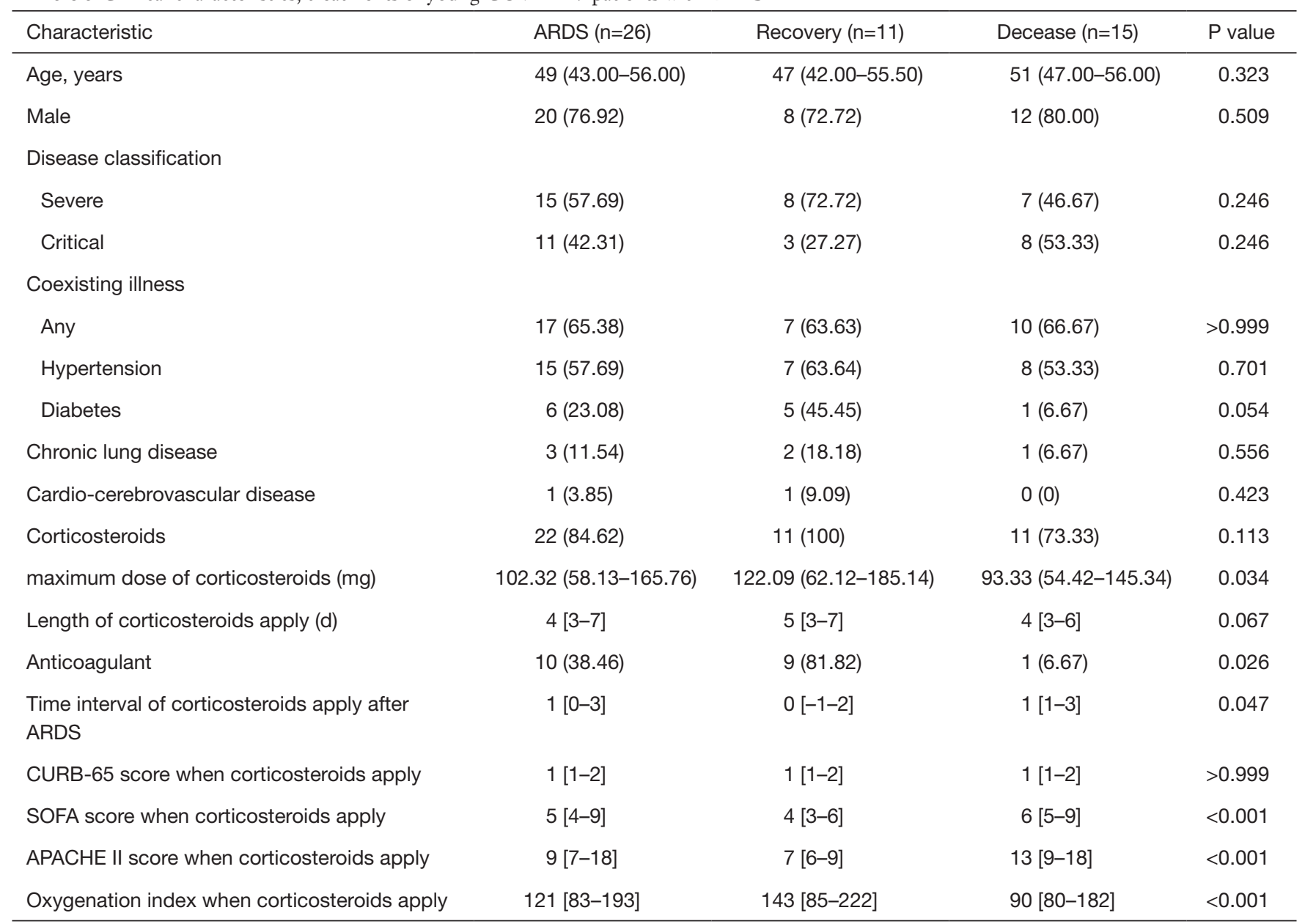

Data are median (IQR), n (\%). COVID-19, coronavirus disease 2019; SOFA, sequential organ failure assessment; ARDS, acute respiratory distress syndrome.

cytokine/chemokine response, known as cytokine storms, are thought to play major role in disease exacerbation (21). That may partly explain the short median time (10.5 days) from illness onset to develop ARDS for individual infected with COVID-19 (12). More interestingly, neutrophilia was observed in $93 \%$ of deceased young patients in our study, and in only $66 \%$ elderly patients who died (not shown). The previous study also demonstrated the neutrophil count continued to increase in COVID-19 patients who died (22). Neutrophils as the main source of cytokine and chemokine may be involved in cytokine storm. The MERS patients with severe pneumonia often rapidly progressed to ARDS. An abnormal increase of neutrophils and macrophages counts were found in their peripheral blood and lung tissues $(20,23)$. Compared with the elderly, young people have stronger immune systems which may contribute to fiercer cytokine storm. In this study, all deceased young patients developed ARDS, perhaps due to excess activation of neutrophils inducing exuberant host inflammatory responses. We noted that leukocytosis, neutrophilia, lymphopenia, elevated levels of infection-related biomarkers were more frequent in fatal cases compared with those who recovered. The increase of NLR was helpful in identify the young patients with poor prognosis which was consistent with the findings from Wang et al. (22). In addition, high mortality in the infected elderly could be partly due to poor conditions and underlying disease which is especially frequent among them.

We also noted that coagulation and organ (e.g., cardiac and liver) dysfunction were more common in young severe patients who died compared with those who recovered. Similarly, patients with MERS had considerable extra- 
Table 6 Risk factors associated with in-hospital mortality of young patients with severe COVID-19

\begin{tabular}{|c|c|c|c|c|}
\hline Variables & \multicolumn{2}{|c|}{ Univariate analysis } & \multicolumn{2}{|c|}{ Multivariate analysis } \\
\hline Male & $4.182(1.038-16.851)$ & 0.044 & & \\
\hline Sputum & $11.000(2.830-42.756)$ & 0.001 & $18.036(1.680-193.592)$ & 0.017 \\
\hline Dyspnea & $18.5(4.220-81.111)$ & $<0.001$ & & \\
\hline Hypertension & $6.204(1.698-22.667)$ & 0.006 & & \\
\hline Heart rate $>100$ beat per minute & $3.083(0.853-11.145)$ & 0.086 & & \\
\hline Respiratory rate $\geq 25$ breaths per minute & $5.333(1.329-21.407)$ & 0.018 & & \\
\hline Oxygenation index $<240 \mathrm{mmHg}$ & $64.750(7.406-565.918)$ & $<0.001$ & & \\
\hline PSI score & $1.101(1.043-1.163)$ & 0.001 & $1.068(1.007-1.134)$ & 0.030 \\
\hline CURB-65 & $16.236(3.809-69.209)$ & $<0.001$ & & \\
\hline SMART-COP & $4.611(2.042-10.410)$ & $<0.001$ & & \\
\hline Leukocytosis & $14.000(2.428-80.731)$ & 0.003 & & \\
\hline Lymphopenia & $6.000(1.319-27.287)$ & 0.020 & & \\
\hline Neutrophils & $1.570(1.224-2.014)$ & $<0.001$ & $1.452(1.043-2.022)$ & 0.027 \\
\hline Neutrophilia & $91.000(10.050-424.002)$ & $<0.001$ & & \\
\hline Neutrophil-to-lymphocyte ratio & $1.332(1.133-1.565)$ & 0.001 & & \\
\hline Elevated ALT & $4.923(1.407-17.221)$ & 0.013 & & \\
\hline Elevated AST & $6.000(1.693-21.262)$ & 0.006 & & \\
\hline CKMB & $5.589(1.529-20.424)$ & 0.009 & & \\
\hline Myohemoglobin & $1.063(1.021-1.107)$ & 0.003 & & \\
\hline Acute liver injury & $16.000(1.622-157.801)$ & 0.018 & & \\
\hline
\end{tabular}

COVID-19, coronavirus disease 2019; SOFA, sequential organ failure assessment; PSI, pneumonia severity index; APTT, activated partial thromboplastin time; FDP, fibrinogen degradation product; ALT, alanine aminotransferase; AST, aspartate amino transferase; FDP, fibrinogen degradation product.

pulmonary organ dysfunction (24), and yet SARS caused primarily pulmonary organ dysfunction (25). One important finding in our study was that level of D-dimer and FDP were tremendously increased in deceased young patients compared to those who recovery. Moreover, level of
D-dimer in deceased young patients was higher than that in the elderly who died (median $6.07 v s .4 .98 \mathrm{mg} / \mathrm{L}$ ). In our study, most young patients who received anticoagulation therapy recovered which are consistent with the findings of Tang et al. (26). Owing to small sample size and potential 

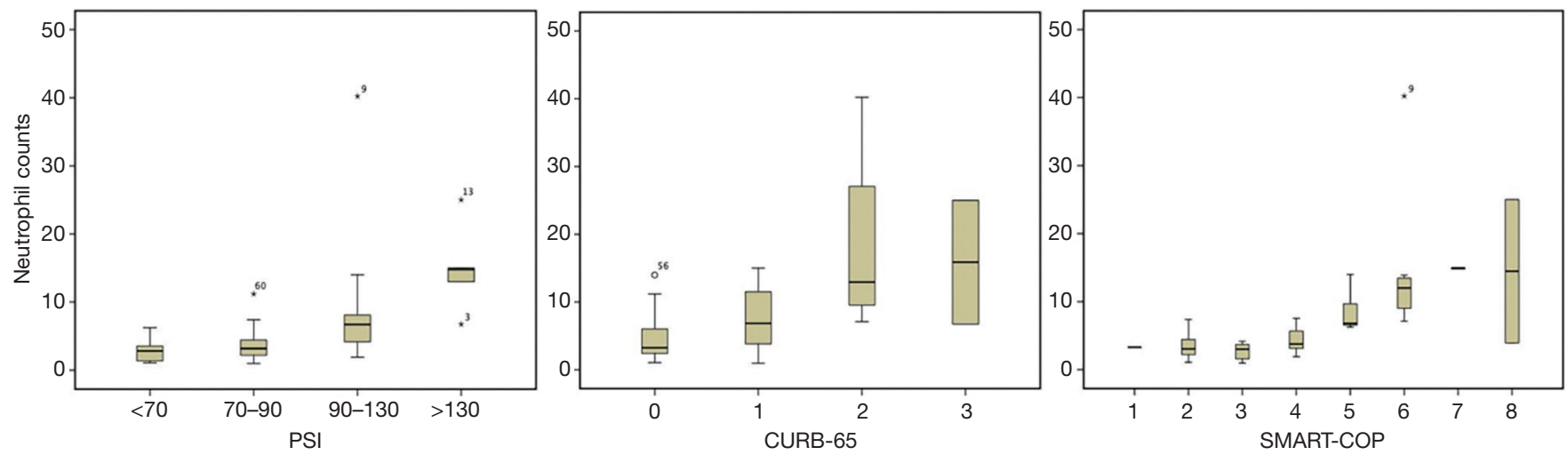

Figure 3 Admission neutrophil counts classified in different severity assessment tools. Boxes represent 25 th-75th percentiles, with horizontal lines and whiskers indicating median values and range, respectively. PSI, pneumonia severity index. The stars indicate extreme value, the circle indicates discrete value.
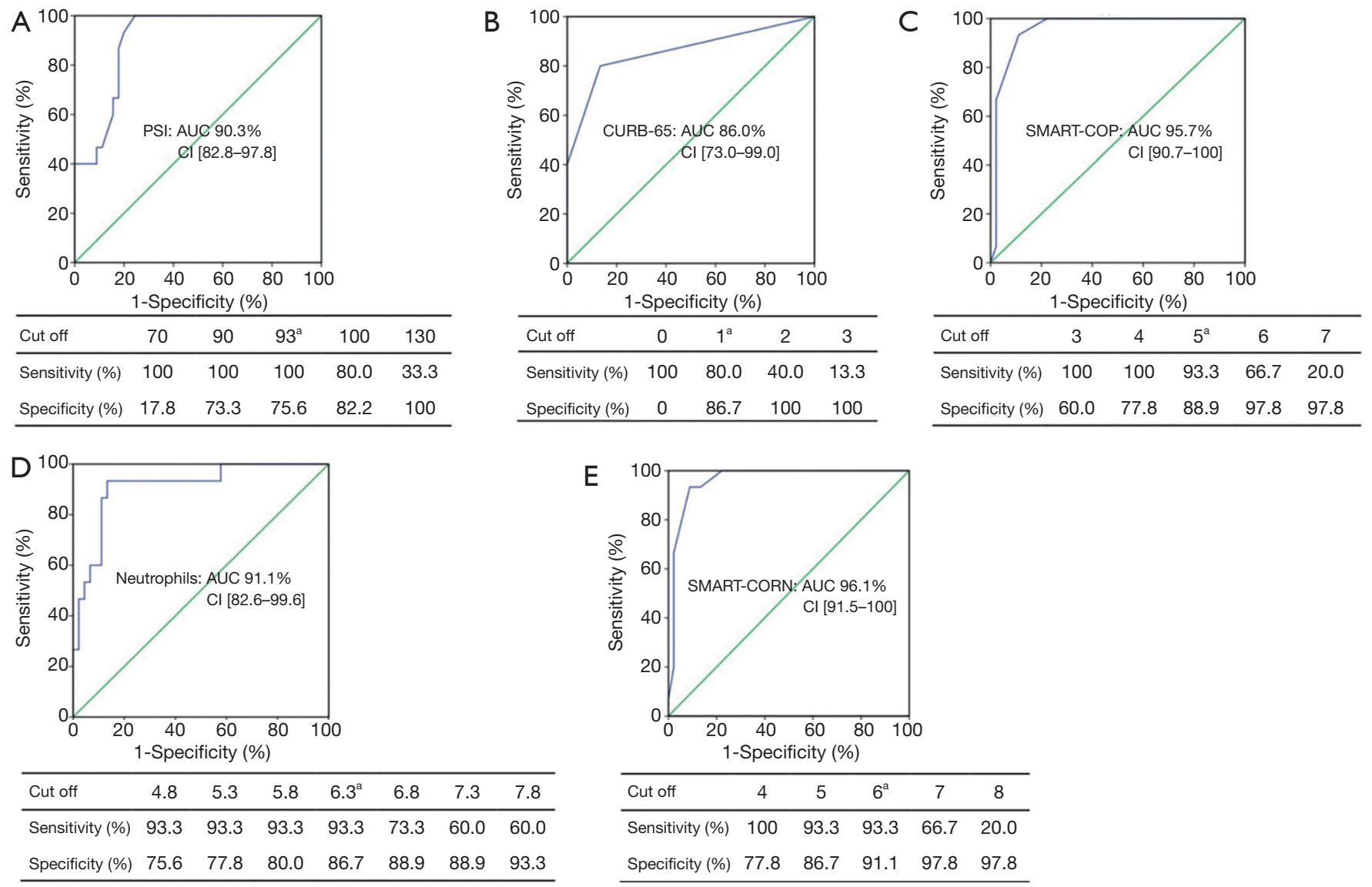

Figure 4 ROC curves for different severity assessment tools in predicting in-hospital mortality. The figure demonstrates comparisons of receiver operating characteristic curves in predicting death. (A) The ability of PSI score to predict mortality. (B) The ability of CURB65 score to predict mortality. (C) The ability of SMART-COP score to predict mortality. (D) The ability of neutrophil counts to predict mortality. (E) The ability of SMART-COPN ${ }^{\mathrm{b}}$ score to predict mortality. ${ }^{\mathrm{a}}$, optimal cutoff according to Youden index; ${ }^{\mathrm{b}}$, SMART-COP score including neutrophil counts $>6.3 \times 10^{9} / \mathrm{L}$, count as 1 point. Tables below demonstrate cut off sensitivities and specificities at specific values. ROC, receiver operating characteristic curve; PSI, pneumonia severity index. 
bias, more comprehensive studies are needed to investigate the effect of anticoagulant therapy for severe COVID-19.

In our current data, a majority of deceased young patients had abnormal oxygenation and dyspnea which caused by pulmonary inflammation and compromised oxygen exchange. Most MERS patients with dyspnea developed severe pneumonia with poor prognosis (24). Generally, young patients with enhanced anoxic tolerance had difficult to aware of the hypoxia in time. We advocate that oxygen saturation monitoring should be recommended for patients with COVID-19 under home quarantine and treatment to prevent further deterioration, especially the young.

Although how SARS-CoV-2 attacks the cardiovascular system remains a mystery, many studies have suggested that cardiac damage was common $(27,28)$. We noted that cardiac damage was more frequent in the elderly than in the young patients which was consistent with the findings of Liu et al. (8), but it also contributed to the death of the young individual with severe COVID-19. We hypothesized that exuberant inflammatory responses were associated with cardiac damage, but not the main factor. Owing to the potential bias, the incidence of cardiac damage in the young patients may be underestimated. Liver injury was also common in young severe COVID-19 patients.

Current pneumonia severity scoring systems, such as pneumonia severity index (PSI) and CURB-65, were developed from risk factors of 30-day mortality (29). Both relied heavily on the age and coexisting illness, so they may be less accurate to predict the severity of young patients with COVID-19. SMART-COP is a relatively simple tool to identify accurately CAP patients who will require IRVS and predict disease severity (30). In our study, a SMARTCOP score of 5 points better predicted the in-hospital mortality of young patients with severe COVID-19 than did PSI and CURB-65. Neutrophil was independent predictors for death of young patients with COVID-19. In our study, SMART-COPN which included neutrophilia in the SMART-COP was superior compared to SMART-COP alone. However, prospective study with large sample size should be conducted to validate the reliability of SMARTCOPN model.

Unfortunately, no specific drugs for COVID-19 were available to date. Corticosteroids therapy are effective in clearing lung consolidation in patients with SARS and most of them were administered high-dose corticosteroids (31). Whereas, the role of corticosteroids in treatment of COVID-9, MERS and even SARS, remains controversial $(32,33)$. In our study, the therapeutic strategy for young patient with severe COVID-19 was not as aggressive as that in the elderly. Yet when they suffered continued deterioration, corticosteroids were administered for rescuing them. Therefore, more deceased young patients were given corticosteroids compared to the recovered. Notably, association of early initiation of corticosteroid therapy (within $48 \mathrm{~h}$ after diagnosed with ARDS), anticoagulation therapy and lower mortality was revealed suggesting that patients with ARDS could benefit from adjuvant early corticosteroid and anticoagulation therapy. Carpagnano et al. (34) suggested that, in COVID-19 patients with moderate-to-severe ARDS using BPAP had more factors associated to all-cause mortality compared to those who underwent CPAP. For the limited patients included in our study, we don't have enough young patients who were treated with noninvasive ventilation for analysis.

In our opinion, the severe young people with poor prognosis should be identified early in their course and given aggressive treatment. Due to a shortage of ventilators at the beginning of COVID-19 outbreak, the proportion of patients receiving mechanical ventilation was only $15 \%$ in our study.

This study has several limitations. Firstly, it was a retrospective single-center study with small sample size. Secondly, more severe cases with poor prognosis were included in the study which may cause selective bias. However, most findings were bolstered by several other studies, our conclusions are still valid. A larger cohort of this population is expected to improve our findings.

In conclusion, SARS-Cov-2 infection in young patients appears to cause exuberant inflammatory responses, leading to compromised oxygen exchange, coagulation and multiorgan dysfunction. ARDS, acute cardiac injury and acute liver injury may also contribute to death. Patients with ARDS could benefit from adjuvant early corticosteroid and anticoagulation therapy. The SMART-COPN model achieved an optimal prediction of mortality and could help clinicians to screen patients with poor prognosis at earlier stage. Prospective study with large sample size to validate the reliability of SMART-COPN model are still needed. As the COVID-19 pandemic evolves, our findings provide guidance for treatment of severe young patients.

\section{Acknowledgments}

Funding: This study was supported by a grant from National Key Research and Development Program of China (2018YFC1313600), Prevention and Treatment of Infection 
in Novel Coronavirus Pneumonia Patients from the Science and Technology Committee, Shanghai Municipal Key Clinical Specialty (shslczdzk02201), and Shanghai TopPriority Clinical Key Disciplines Construction Project (2017ZZ02013).

\section{Footnote}

Reporting Checklist: The authors have completed the STROBE reporting checklist. Available at http://dx.doi. org/10.21037/jtd-21-120

Data Sharing Statement: Available at http://dx.doi. org/10.21037/jtd-21-120

Conflicts of Interest: All authors have completed the ICMJE uniform disclosure form (available at http://dx.doi. org/10.21037/jtd-21-120). The authors have no conflicts of interest to declare.

Ethical Statement: The authors are accountable for all aspects of the work in ensuring that questions related to the accuracy or integrity of any part of the work are appropriately investigated and resolved. The study was conducted in accordance with the Declaration of Helsinki (as revised in 2013). This study was approved by the ethics committee of Renmin Hospital, Wuhan University, China (WDRY2020-K048). Individual patient informed consent was waived due to given the non-interventional nature of the study. The identification of patients was anonymized.

Open Access Statement: This is an Open Access article distributed in accordance with the Creative Commons Attribution-NonCommercial-NoDerivs 4.0 International License (CC BY-NC-ND 4.0), which permits the noncommercial replication and distribution of the article with the strict proviso that no changes or edits are made and the original work is properly cited (including links to both the formal publication through the relevant DOI and the license). See: https://creativecommons.org/licenses/by-nc-nd/4.0/.

\section{References}

1. World Health Organization. Coronavirus disease 2019 (COVID-19) Situation Report-update 92. 2020 [updated 21 April 2020]. Available online: https:// www.who.int/docs/default-source/coronaviruse/ situation-reports/20200421-sitrep-92-covid-19. pdf?sfvrsn=38e6b06d_4

2. Epidemiology Working Group for NCIP Epidemic Response, Chinese Center for Disease Control and Prevention. The epidemiological characteristics of an outbreak of 2019 novel coronavirus diseases (COVID-19) in China. Zhonghua Liu Xing Bing Xue Za Zhi 2020;41:145-51.

3. Wu JT, Leung K, Bushman M, et al. Estimating clinical severity of COVID-19 from the transmission dynamics in Wuhan, China. Nature Med 2020;26:506-10.

4. Ferguson NM, Laydon D, Nedjati-Gilani G, et al. Impact of non-pharmaceutical interventions (NPIs) to reduce COVID19 mortality and healthcare demand. Available online: https://www.imperial.ac.uk/media/imperialcollege/medicine/sph/ide/gida-fellowships/ImperialCollege-COVID19-NPI-modelling-16-03-2020.pdf

5. Weiss $\mathrm{P}$, Murdoch DR. Clinical course and mortality risk of severe COVID-19. Lancet 2020;395:1014-5.

6. Wu C, Chen XY, Cai YP, et al. Risk factors associated with acute respiratory distress syndrome and death in patients with coronavirus disease 2019 pneumonia in Wuhan, China. JAMA Intern Med 2020;180:934-43.

7. Rodriguez-Morales AJ, Cardona-Ospina JA, GutierrezOcampo E, et al. Clinical, laboratory and imaging features of COVID-19: a systematic review and meta-analysis. Travel Med Infect Dis 2020;34:101623.

8. Liu K, Chen Y, Lin R, et al. Clinical features of COVID-19 in elderly patients: A comparison with young and middle-aged patients. J Infect 2020;80:e14-e18.

9. Zhu T, Wang Y, Zhou S, et al. A Comparative Study of Chest Computed Tomography Features in Young and Older Adults With Corona Virus Disease (COVID-19). J Thorac Imaging 2020;35:W97-W101.

10. Feng Y, Ling Y, Bai T, et al. COVID-19 with Different Severities: A Multicenter Study of Clinical Features. Am J Respir Crit Care Med 2020;201:1380-8.

11. A New coronavirus pneumonia prevention and control program (7th ed) (in Chinese). 2020. Available online: http://www.nhc.gov.cn/xcs/zhengcwj/202003/46c9294a7df e4cef80dc7f5912eb1989/files/ce3e6945832a438eaae41535 0a8ce964.pdf

12. Huang C, Wang Y, Li X, et al. Clinical features of patients infected with 2019 novel coronavirus in Wuhan, China. Lancet 2020;395:497-506.

13. World Health Organization. Clinical management of severe acute respiratory infection when Novel coronavirus $(\mathrm{nCoV})$ infection is suspected: interim guidance. 2020. Available online: https://www.who.int/publications- 
detail/clinical-management-of-severe-acute-respiratoryinfection-when-novel-coronavirus-(ncov)-infection-issuspected

14. Khwaja A. KDIGO clinical practice guidelines for acute kidney injury. Nephron Clin Pract 2012;120:c179-84.

15. Januzzi JL, van Kimmenade R, Lainchbury J, et al. NTproBNP testing for diagnosis and short-term prognosis in acute destabilized heart failure: an international pooled analysis of 1256 patients: the International Collaborative of NT-proBNP Study. Eur Heart J 2006;27:330-7.

16. Chan TY, Miu KY, Tsui CK, et al. A comparative study of clinical features and outcomes in young and older adults with severe acute respiratory syndrome. J Am Geriatr Soc 2004;52:1321-5.

17. Jain S, Kamimoto L, Bramley AM, et al. Hospitalized patients with $2009 \mathrm{H} 1 \mathrm{~N} 1$ influenza in the United States, April-June 2009. New Engl J Med 2009:361:1935-44.

18. Qin C, Zhou L, Hu Z, et al. Dysregulation of Immune Response in Patients With Coronavirus 2019 (COVID-19) in Wuhan, China. Clin Infect Dis 2020;71:762-8.

19. Lau YL, Peiris JS. Pathogenesis of severe acute respiratory syndrome. Curr Opin Immunol 2005;17:404-10.

20. Zhou J, Chu H, Li C, et al. Active replication of Middle East respiratory syndrome coronavirus and aberrant induction of inflammatory cytokines and chemokines in human macrophages: implications for pathogenesis. J Infect Dis 2014;209:1331-42.

21. Mehta P, McAuley DF, Brown M, et al. COVID-19: consider cytokine storm syndromes and immunosuppression. Lancet 2020;395:1033-4.

22. Wang D, Hu B, Hu C, et al. Clinical Characteristics of 138 Hospitalized Patients With 2019 Novel CoronavirusInfected Pneumonia in Wuhan, China. JAMA 2020;323:1061-9.

23. Min CK, Cheon S, Ha NY, et al. Comparative and kinetic analysis of viral shedding and immunological responses in MERS patients representing a broad spectrum of disease severity. Sci Rep 2016;6:25359.

24. Arabi YM, Arifi AA, Balkhy HH, et al. Clinical course

Cite this article as: Liu Z, Liu J, Ye L, Yu K, Luo Z, Liang C, Cao J, Wu X, Li S, Zhu L, Xiang G. Predictors of mortality for hospitalized young adults aged less than 60 years old with severe COVID-19: a retrospective study. J Thorac Dis 2021;13(6):36283642. doi: $10.21037 /$ jtd-21-120 and outcomes of critically ill patients with Middle East respiratory syndrome coronavirus infection. Ann Int Med 2014;160:389-97.

25. Fowler RA, Lapinsky SE, Hallett D, et al. Critically ill patients with severe acute respiratory syndrome. JAMA 2003;290:367-73.

26. Tang N, Bai H, Chen X, et al. Anticoagulant treatment is associated with decreased mortality in severe coronavirus disease 2019 patients with coagulopathy. J Thromb Haemost 2020;18:1094-9.

27. Fried JA, Ramasubbu K, Bhatt R, et al. The Variety of Cardiovascular Presentations of COVID-19. Circulation 2020;141:1930-6.

28. Shi S, Qin M, Shen B, et al. Association of Cardiac Injury With Mortality in Hospitalized Patients With COVID-19 in Wuhan, China. JAMA Cardiol 2020;5:802-10.

29. Kim HI, Kim SW, Chang HH, et al. Mortality of community-acquired pneumonia in Korea: assessed with the pneumonia severity index and the CURB-65 score. J Korean Med Sci 2013;28:1276-82.

30. Charles PG, Wolfe R, Whitby M, et al. SMART-COP: a tool for predicting the need for intensive respiratory or vasopressor support in community-acquired pneumonia. Clin Infect Dis 2008;47:375-84.

31. Tsang KW, Lam WK. Management of severe acute respiratory syndrome: the Hong Kong University experience. Am J Respir Crit Care Med 2003;168:417-24.

32. Russell CD, Millar JE, Baillie JK. Clinical evidence does not support corticosteroid treatment for 2019-nCoV lung injury. Lancet 2020;395:473-5.

33. Shang L, Zhao J, Hu Y, et al. On the use of corticosteroids for 2019-nCoV pneumonia. Lancet 2020;395:683-4.

34. Carpagnano GE, Buonamico E, Migliore G, et al. Bilevel and continuous positive airway pressure and factors linked to all-cause mortality in COVID-19 patients in an intermediate respiratory intensive care unit in Italy. Expert Rev Respir Med 2020. doi: 10.1080/17476348.2021.1866546. 


\section{Supplementary}

Table S1 Diagnostic criterion of clinical types for COVID-19 (11)

\begin{tabular}{l}
\hline Diagnostic criterion \\
\hline The clinical symptoms are mild with no abnormal radiological findings \\
Fever and respiratory symptom are presented with pneumonia on radiography \\
If any of the following conditions is met: \\
Shortness of breath, respiratory rate $\geq 30 / \mathrm{min} ;$ \\
Oxygen saturation at rest $\leq 93 \%$; \\
$\mathrm{PaO}_{2} / \mathrm{FiO} \mathrm{O}_{2} \leq 300 \mathrm{mmHg}$ \\
Patients with $>50 \%$ lesions progression within 24 to 48 hours in chest CT scan \\
If any of the following conditions is met: \\
Respiratory failure occurs and mechanical ventilation is required; \\
Shock occurs; \\
Combined with other organ function failure requiring monitoring and treatment in ICU
\end{tabular}

$\mathrm{PaO}_{2}$, Partial pressure of arterial oxygen; $\mathrm{FIO}_{2}$, fraction of inspired oxygen; ICU, intensive care unit.

Table S2 Diagnostic criteria of complications for COVID-19

\begin{tabular}{|c|c|}
\hline Diagnostic criterion & Complication \\
\hline \multicolumn{2}{|l|}{$\begin{array}{l}\text { Chest imaging (radiograph, CT scan, or lung ultrasound): bilateral opacities, not fully explained by } \\
\text { volume overload, lobar or lung collapse, or nodules. }\end{array}$} \\
\hline \multicolumn{2}{|l|}{$\begin{array}{l}\text { Origin of pulmonary infiltrates: respiratory failure not fully explained by cardiac failure or fluid overload. } \\
\text { Need objective assessment (e.g., echocardiography) to exclude hydrostatic cause of infiltrates/oedema if } \\
\text { no risk factor present. }\end{array}$} \\
\hline \multicolumn{2}{|l|}{ Mild ARDS: $200 \mathrm{mmHg}<\mathrm{PaO}_{2} / \mathrm{FiO}_{2} \mathrm{a} \leq 300 \mathrm{mmHg}$ (with PEEP or CPAP $\geq 5 \mathrm{cmH}_{2} \mathrm{O}$, or non-ventilated) } \\
\hline \multicolumn{2}{|l|}{ Moderate ARDS: $100 \mathrm{mmHg}<\mathrm{PaO} 2 / \mathrm{FiO}_{2} \leq 200 \mathrm{mmHg}$ (with PEEP $\geq 5 \mathrm{cmH}_{2} \mathrm{O}$, or non-ventilated) } \\
\hline \multicolumn{2}{|l|}{ Severe ARDS: $\mathrm{PaO}_{2} / \mathrm{FiO}_{2} \leq 100 \mathrm{mmHg}$ (with PEEP $\geq 5 \mathrm{cmH}_{2} \mathrm{O}$, or non-ventilated) } \\
\hline \multicolumn{2}{|l|}{ When $\mathrm{PaO}_{2}$ is not available, $\mathrm{SpO}_{2} / \mathrm{FiO}_{2} \leq 315$ suggests ARDS (including in non-ventilated patients). } \\
\hline $\begin{array}{l}\text { Identified on basis of the highest serum creatinine level according to the kidney disease improving global } \\
\text { outcomes classification. }\end{array}$ & Acute kidney injury (14) \\
\hline $\begin{array}{l}\text { Persisting hypotension despite volume resuscitation, requiring vasopressors to maintain MAP } \geq 65 \mathrm{mmHg} \\
\text { and serum lactate level }>2 \mathrm{mmol} / \mathrm{L} \text {. }\end{array}$ & Septic shock (13) \\
\hline
\end{tabular}

$\mathrm{PaO}_{2}$, Partial pressure of arterial oxygen; $\mathrm{FIO}_{2}$, fraction of inspired oxygen; ARDS, acute respiratory distress syndrome; PEEP, positive end expiratory pressure; CAPA, continuous positive airway pressure; MAP, mean artery pressure. 


\begin{tabular}{|c|c|c|c|c|c|c|c|c|c|c|c|c|}
\hline Case & Age (years) & Sex & Initial symptoms and signs & $\operatorname{Time}^{\mathrm{a}}$ (day) & Disease type & Coexisting illness & Methylprednisolone ${ }^{b}$ & Antiviral therapy & Antibacterial therapy & Other therapy & Complications & Time $^{c}$ (days) \\
\hline 1 & 31 & M & Fever $/ \max 39^{\circ} \mathrm{C}$ & 13 & Critical & No & $80 \mathrm{mg}$ BID & Oseltamivir/ribavirin & $\begin{array}{l}\text { Cefoperazone/moxifloxacin/ } \\
\text { imipenem }\end{array}$ & rhIFN $\alpha / H F N C$ & ARDS/PT/PD & 5 \\
\hline 2 & 34 & $\mathrm{~F}$ & Dyspnea & 5 & Critical & Malignancy & 80mg QD & Ribavirin & $\begin{array}{l}\text { Cefoperazone/moxifloxacin/ } \\
\text { imipenem }\end{array}$ & HFNC & ARDS/ALI/bacteremia & 5 \\
\hline 3 & 47 & M & Dry Cough & 7 & Critical & $H T /$ schizophrenia & 40mg QD & Oseltamivir/ribavirin & $\begin{array}{l}\text { Cefperazone-Sulbactam/ } \\
\text { moxifloxacin }\end{array}$ & Lianhuaqingwen/HFNC & ARDS & 1 \\
\hline 4 & 47 & M & Fever $/ \max 39^{\circ} \mathrm{C}$ & 13 & Severe & Bronchiectasis & $40 \mathrm{mg}$ Q8H & Ribavirin & Cefoperazone/moxifloxacin & $\begin{array}{l}\text { rhlFNa/lianhuaqingwen/ } \\
\text { mechanical ventilation }\end{array}$ & ARDS & 7 \\
\hline 5 & 47 & M & Fever $/ \operatorname{Tmax} 38.8^{\circ} \mathrm{C}$ & 18 & Critical & No & $40 \mathrm{mg} \mathrm{BID}$ & Arbidol & No & $\begin{array}{l}\text { Lianhuaqingwen/mechanical } \\
\text { ventilation }\end{array}$ & ARDS & 1 \\
\hline 6 & 50 & $\mathrm{~F}$ & Fever $/ \max 38^{\circ} \mathrm{C}$ & 9 & Severe & No & No & Ribavirin & Moxifloxacin & $\begin{array}{l}\text { rhlFNa/lanhuaqingwen/ } \\
\text { HFNC }\end{array}$ & ARDS & 4 \\
\hline 7 & 51 & M & Fever/Tmax38.9 ${ }^{\circ} \mathrm{C}$ & 13 & Severe & No & 40mg QD & Arbidol & $\begin{array}{l}\text { Moxifloxacin/meropenem/ } \\
\text { Vancomycin }\end{array}$ & Andrographolide/HFNC & ARDS & 3 \\
\hline 8 & 51 & M & Fever/Tmax38.9 ${ }^{\circ} \mathrm{C}$ & 9 & Severe & HT/DM & No & Oseltamivir & Moxifloxacin & Lianhuaqingwen/HFNC & $\begin{array}{l}\text { ARDS/ } \\
\text { Hyperglycemia }\end{array}$ & 7 \\
\hline 9 & 52 & $\mathrm{~F}$ & Fever $/ \operatorname{Tmax} 38.5^{\circ} \mathrm{C}$ & 10 & Severe & $\begin{array}{l}\text { HT/essential } \\
\text { thrombocythemia }\end{array}$ & $40 \mathrm{mg} \mathrm{BID}$ & Ribavirin & Cefoperazone/moxifloxacin & HFNC & ARDS & 1 \\
\hline 10 & 54 & M & Fever $/ \max 39^{\circ} \mathrm{C}$ & 6 & Critical & HT & $60 \mathrm{mg}$ BID & $\begin{array}{l}\text { Oseltamivir/arbidol/ } \\
\text { ganciclovir }\end{array}$ & $\begin{array}{l}\text { Cefoperazone/moxifloxacin/ } \\
\text { azithromycin }\end{array}$ & $\begin{array}{l}\text { Lianhuaqingwen/mechanical } \\
\text { ventilation }\end{array}$ & ARDS/AHI/Niral myocarditis & 10 \\
\hline 12 & 56 & M & Fever $/ \max 39^{\circ} \mathrm{C}$ & 7 & Critical & HT/Uremia & No & Arbidol & Moxifloxacin & $\begin{array}{l}\text { Lianhuaqingwen/CRRT/ } \\
\text { HFNC }\end{array}$ & ARDS/AHI/AKI & 8 \\
\hline 13 & 56 & M & Fatigue & 15 & Critical & HT & 80mg QD & No & Imipenem/vancomycin & Fluconazole/HFNC & ARDS/AHI/DIC & 3 \\
\hline 14 & 57 & M & Fever $/ \max 38^{\circ} \mathrm{C}$ & 11 & Critical & No & No & Oseltamivir/ribavirin & Moxifloxacin & Lianhuaaingwen/HFNC & ARDS/ALI & 2 \\
\hline 15 & 58 & M & Fever $/ \max 39^{\circ} \mathrm{C}$ & 26 & Severe & HT & 40mg BID & Oseltamivir/arbidol & Moxifloxacin & Lianhuaqingwen/HFNC & ARDS & 5 \\
\hline
\end{tabular}

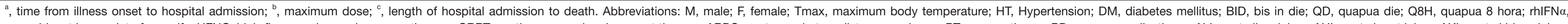

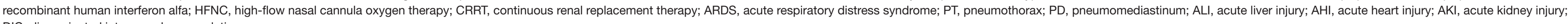
DIC, disseminated intravascular coagulation. 

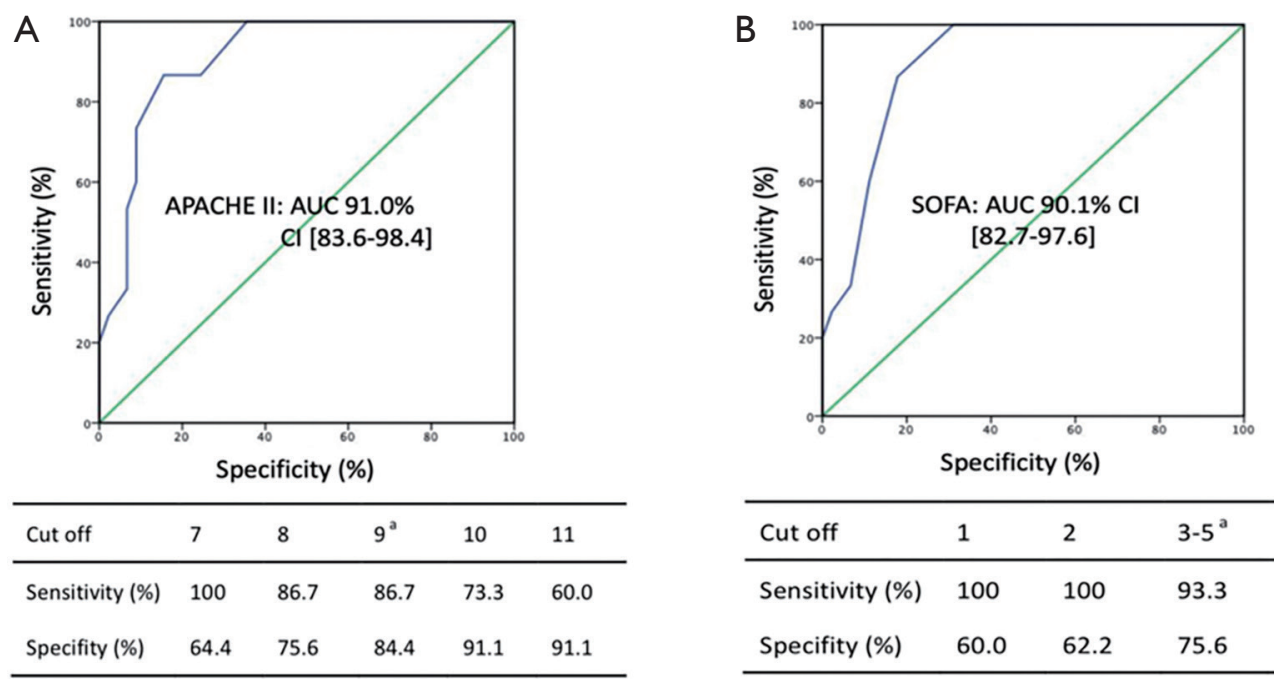

\begin{tabular}{llllll}
\hline Cut off & 1 & 2 & $3-5^{\mathrm{a}}$ & 6 & 7 \\
\hline Sensitivity (\%) & 100 & 100 & 93.3 & 60.0 & 33.3 \\
Specifity (\%) & 60.0 & 62.2 & 75.6 & 88.9 & 93.3 \\
\hline
\end{tabular}

Figure S1 ROC curves for APACHE II and SOFA score in predicting in-hospital mortality. Figure demonstrates comparisons of receiver operating characteristic curves in predicting mortality. (A) APACHE II score ability to predict mortality. (B) SOFA score ability to predict mortality. An optimal cutoff according to Youden index. Tables below demonstrate cut off sensitivities and specificities at specific values. ROC, receiver operating characteristic curve; SOFA, sequential organ failure assessment. 